\title{
BMJ Open Physical activity, diet and BMI in children aged 6-8 years: a cross-sectional analysis
}

\author{
Laura Basterfield, ${ }^{1}$ Angela R Jones, ${ }^{1}$ Kathryn N Parkinson, ${ }^{1}$ Jessica Reilly, ${ }^{1}$ Mark \\ S Pearce, ${ }^{2}$ John J Reilly, ${ }^{3}$ Ashley J Adamson, ${ }^{1}$ The Gateshead Millennium Study \\ Core Team
}

To cite: Basterfield L, Jones AR, Parkinson KN, et al. Physical activity, diet and BMI in children aged 6-8 years:

a cross-sectional analysis. BMJ Open 2014;4:e005001. doi:10.1136/bmjopen-2014005001

- Prepublication history for this paper is available online. To view these files please visit the journal online (http://dx.doi.org/10.1136/ bmjopen-2014-005001).

Received 8 February 2014 Revised 17 April 2014 Accepted 22 April 2014

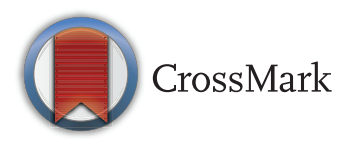

${ }^{1}$ Institute of Health \& Society, Human Nutrition Research Centre, Newcastle University, Newcastle upon Tyne, UK ${ }^{2}$ Institute of Health \& Society, Newcastle University, Sir James Spence Institute, Royal Victoria Infirmary, Newcastle upon Tyne, UK ${ }^{3}$ Physical Activity for Health Group, School of Psychological Sciences and Health, University of Strathclyde, Glasgow, UK

\section{Correspondence to} Professor Ashley J Adamson; ashley.adamson@ncl.ac.uk

\section{ABSTRACT}

Objective: To assess relationships between current physical activity (PA), dietary intake and body mass index (BMI) in English children.

Design and setting: Longitudinal birth cohort study in northeast England, cross-sectional analysis.

Participants: 425 children (41\% of the original cohort) aged $6-8$ years ( $49 \%$ boys).

Main outcome measures: PA over 7 days was measured objectively by an accelerometer; three categories of PA were created: 'active' $\geq 60 \mathrm{~min} /$ day moderate-to-vigorous-intensity PA (MVPA); 'moderately active' 30-59 min/day MVPA; 'inactive' $<30 \mathrm{~min} /$ day MVPA. Dietary intake over 4 days was measured using a prospective dietary assessment tool which incorporated elements of the food diary and food frequency methods. Three diet categories were created: 'healthy', 'unhealthy' and 'mixed', according to the number of portions of different foods consumed. Adherence to the ' 5 -a-day' recommendations for portions of fruit and vegetables was also assessed. Children were classified as 'healthy weight' or 'overweight or obese' (OW/OB) according to International Obesity Taskforce cutpoints for BMI. Associations between weight status and PA/diet categories were analysed using logistic regression.

Results: Few children met the UK-recommended guidelines for either MVPA or fruit and vegetable intake, with just $7 \%$ meeting the recommended amount of MVPA of $60 \mathrm{~min} /$ day, and $3 \%$ meeting the 5-a-day fruit and vegetable recommendation. Higher PA was associated with a lower $\mathrm{OR}$ for OW/OB in boys only $(0.20,95 \% \mathrm{Cl} 0.04$ to 0.88$)$. There was no association detected between dietary intake and OW/OB in either sex.

Conclusions: Increasing MVPA may help to reduce OW/OB in boys; however, more research is required to examine this relationship in girls. Children are not meeting the UK guidelines for diet and PA, and more needs to be done to improve this situation.

\section{INTRODUCTION}

Childhood obesity (OB) is a major public health challenge in the UK and around the

\section{Strengths and limitations of this study}

- Direct objectively measured physical activity and observed dietary intake.

- Direct measures of body composition.

- Population-based birth cohort socioeconomically representative of northeast England.

- Ethnically homogeneous sample which reduces generalisability.

- Cross-sectional so cannot determine direction of causality.

world, with governments increasingly involving themselves in different strategies to reduce excess weight in the population. ${ }^{1}{ }^{2}$ Recent findings from the National Child Measurement Programme (2011-2012) regarding the prevalence of childhood overweight $(\mathrm{OW})$ and $\mathrm{OB}$ are concerning, ${ }^{3}$ especially in northeast England, which is the worst-affected region of England outside of London, where $24.5 \%$ of 4 -5-year-olds and $37 \%$ of $10-11$-year-olds are OW/OB. There remains a limited understanding of the timing and causes of childhood $\mathrm{OB}$, and there is an urgent need for effective preventive strategies.

Current UK health recommendations state that children should accumulate at least 60 min of moderate-to-vigorous-intensity physical activity (MVPA) per day, with vigorousintensity activities performed on at least 3 days/week. ${ }^{4}$ This recommendation is based on evidence from intervention studies. ${ }^{5}$ However, recent evidence suggests that the majority of children fail to meet this target, with $51 \%$ of English 4-10-year-old boys and $34 \%$ of $4-10$-year-old girls achieving the physical activity (PA) recommendations as measured by an accelerometer, figures which dropped to $7 \%$ and $0 \%$, respectively, among 11-15-year-olds. ${ }^{6}$ In addition, children should consume a healthy balanced diet which 
contains a variety of foods, including at least five portions of fruit and vegetables per day, plenty of starchy foods (particularly wholegrain varieties), some protein-rich foods and some milk and dairy foods. It is also recommended that foods high in fat (especially saturated fat), salt and sugar should only be consumed in small amounts. ${ }^{7}$ Data from the National Diet and Nutrition Survey in 2010 indicated that children aged 4-10 years consume an average of $173 \mathrm{~g}$ of fruit and vegetables daily, equivalent to $2.280 \mathrm{~g}$ portions (or 2.8 including fruit juice). ${ }^{8}$ Data from longitudinal cohorts are beginning to uncover the associations between low levels of PA and unfavourable body composition, for example, Janz et $a l^{9}$ but data on the relationship between diet/dietary components and body composition have so far been equivocal, as reviewed by Must $e t a l^{10}$ This may be due to the contrasting methods of dietary assessment and analysis and the complexity of dietary patterns; given the importance of energy balance in maintenance of a healthy body weight, it is vital that measurement of dietary intake continues to be improved. Evidence of the impact of objectively measured PA/sedentary behaviour (SB) and food intake on body composition in primary school-age children is lacking, with most studies measuring either PA or food intake. A recent Scottish study assessed the effect of dietary patterns and PA on body mass index (BMI), ${ }^{11}$ but used a questionnaire that is known to overestimate time spent in PA. ${ }^{12}$ The authors did not find a consistent association between dietary patterns or time spent in PA and BMI group. ${ }^{11}$

The primary aim of the present study was to describe the relationship between OW and OB, BMI, PA and dietary habits in a sample of children that are socioeconomically representative of northeast England. ${ }^{13}$

\section{METHODS}

\section{Participants}

The Gateshead Millennium Study (GMS) cohort originally consisted of 1029 babies and their families and is described in detail elsewhere. ${ }^{13}$ Briefly, all mothers resident in Gateshead who gave birth within prespecified recruiting weeks between June 1999 and May 2000 were invited to take part; $81 \%(\mathrm{n}=1011)$ agreed. Participants were mostly from the white ethnic majority $(98 \%)$. Data collection for the present study involved a variety of lifestyle and anthropometric measures, and took place between October 2006 and December 2007 when the children were aged $6-8$ years. The data presented are crosssectional from the 6-8-year collection phase of the GMS. Parents provided informed written consent for their child's participation and children gave their written assent.

\section{Measures}

$\mathrm{PA}$ and $\mathrm{SB}$

$\mathrm{PA}$ and $\mathrm{SB}$ were objectively measured using Actigraph GT1M accelerometers (Actigraph LLC, Pensacola, Florida, USA) attached to an elastic belt and worn on the right hip as described previously. ${ }^{14}$ Children were asked to wear the accelerometer during waking hours for 7 days and to remove it only for water-based activities. Parents were asked to complete a timelog detailing when the accelerometer had been worn.

The accelerometers collected data in $15 \mathrm{~s}$ sampling intervals (epochs); prior to analysis, the data were collapsed to $60 \mathrm{~s}$ epochs. Data were verified manually using the timelog and accelerometry output as described previously $^{12}$ to delete occasional periods of non-wear time.

Three constructs of PA and one of SB were generated: total volume of activity (expressed as mean daily accelerometer counts per minute, cpm), MVPA daily, equivalent to energy expenditure in excess of approximately three times resting energy expenditure (expressed as minutes/ day and percentage of daily time spent in MVPA) and SB (equivalent to no translocation of the trunk ${ }^{15}$ (expressed as percentage of daily time spent in $\mathrm{SB}$ )).

The cutpoint of $\geq 3200 \mathrm{cpm}^{16}$ was used to define MVPA and $<1100 \mathrm{cpm}^{17}$ was used to define SB. The Actigraph GT1M model has been shown to have a consistent $9 \%$ bias relative to model $7164^{18}$ from which the cutpoints were derived, so a $+9 \%$ correction was applied to the raw accelerometry data before applying cutpoints. Of 606 accelerometers given out, 510 were worn for at least 3 days and for at least $6 \mathrm{~h} /$ day $^{19}$ and thus were deemed eligible for analysis in the present study.

\section{Dietary intake}

Food intake in the children was assessed over 4 days (2 weekdays and 2 weekend days) using the 'Food Assessment in Schools Tool' (FAST) food diary. ${ }^{20}$ The FAST food diary is a prospective dietary assessment method which incorporates elements of the food diary and the food frequency methods and was specifically designed to assess the diets of primary school children. Briefly, each day is split into six timeslots, each containing a simple tick list of up to 50 foods commonly eaten by children of this age. ${ }^{21}$ Space for additional foods was also provided. Researchers and lay observers recorded food intake for each child during the school day, and parents and other carers recorded food intake at all other times. No interviews or estimations of portion size were required during data collection; average agespecific and sex-specific portion sizes for all foods consumed were ascertained using relevant UK National Diet and Nutrition Survey data. ${ }^{20} 21$ This method allowed analysis of food choice at an individual level but not of energy intake.

A 'healthy' and 'unhealthy' dietary indicator score was created for each of the 4 days, and a daily mean calculated. The 'healthy' indicator (HI) score was calculated by summing the number of portions consumed of the following foods: wholemeal bread; non-high sugar wholegrain breakfast cereals; fruit; vegetables; semiskimmed milk as a drink; semi-skimmed milk; nonprocessed meat and fish products; beans and pulses; water and white bread with added fibre. The 'unhealthy' 
indicator (UI) score was calculated by summing the number of portions consumed of the following foods: white bread; high-sugar refined breakfast cereals; fried chips; biscuits; confectionery, cakes and sweet puddings; full-fat milk as a drink; full-fat milk; processed meat and fish products; full-sugar cordial or squash; full-sugar carbonated drinks; chocolate/milkshake powder; crisps and savoury snacks and sugar. A cereal was categorised as 'non-high sugar' if it contained $<5 \mathrm{~g}$ sugar $/ 100 \mathrm{~g}$ and 'high sugar' if it contained $>15 \mathrm{~g}$ sugar $/ 100 \mathrm{~g}$ as manufactured. The addition of discretionary sugar was not taken into account when categorising cereals. To assess adherence to dietary guidelines, fruit and vegetable consumption was measured in $80 \mathrm{~g}$ amounts, fruit juice in $150 \mathrm{~mL}$ portions. Only one portion of fruit juice may count towards daily fruit and vegetable intake. ${ }^{7}$

\section{Anthropometry}

All body measurements were taken in duplicate with the children in light indoor clothing, without socks and shoes. Height was measured to $0.1 \mathrm{~cm}$ with a Leicester portable height measure (Chasmors, London, UK), waist to $0.1 \mathrm{~cm}$ at the minimum circumference between the lowest rib and iliac crest, and weight to $0.1 \mathrm{~kg}$ using a TANITA TBF 300MA body fat analyser (Chasmors, London, UK). BMI was calculated as $\left(\mathrm{wt}(\mathrm{kg}) / \mathrm{ht}\left(\mathrm{m}^{2}\right)\right)$. Categories of underweight, healthy weight, OW and OB were calculated according to age-specific and sex-specific International Obesity Taskforce (IOTF) criteria. ${ }^{22} 23$

\section{Statistical analysis}

The sample size for the current cross-sectional study was fixed by the size of the cohort, participant attrition and those children providing complete data for PA, dietary intake and anthropometry at this data sweep.

Analysis was performed using SPSS V.17 and STATA V.10. Shapiro-Wilk tests assessed the normality of distribution of variables. As data were skewed, Mann-Whitney $\mathrm{U}$ tests were performed to test for differences between sexes and Wilcoxon rank tests to assess differences in weekend and weekday PA/SB. Median and IQRs were reported unless otherwise stated.
Logistic regression was used to predict the likelihood of being OW/OB at different levels of PA and with different dietary indicator scores. Children were assigned to one of the three PA categories: (1) 'active': those who met the $\geq 60 \mathrm{~min} /$ day guideline (this figure was generated by dividing the total amount of MVPA for the week by the number of days the accelerometer was worn); (2) 'moderately active': between 30 and $60 \mathrm{~min} /$ day; (3) 'inactive': less than $30 \mathrm{~min} /$ day. Children were also assigned to one of the three dietary categories: (1) 'healthy': those children whose HI score was $\geq$ the median and whose UI score was < the median; (2) 'unhealthy': those children whose UI score was $\geq$ the median and whose HI score < the median; (3) 'mixed': those diets which neither met the criteria for a 'healthy' diet nor for an 'unhealthy' diet. Children were lastly classified by BMI as: (1) not OW/OB; (2) OW/OB. ORs and corresponding 95\% CIs were reported. Significance was set at $\mathrm{p}<0.05$. Sex was included in the regression analysis as a potential confounder. Townsend score from birth (a measure of deprivation) was unrelated to any of the variables and thus not included in the final analysis.

\section{RESULTS}

Overall, 510 children completed sufficient accelerometry recording; 474 children returned completed FAST food diaries and 597 children had anthropometry measurements. Data from all three domains were provided by 425 children and were used in the analysis. There were no significant differences in food intake, PA or BMI between children providing complete records and those who did not. Children had a mean age of 7.4 years (range 6.4-8.4). Characteristics of the sample are displayed in table 1 .

Using IOTF cut-offs, ${ }^{22} 24 \%$ of the children were $\mathrm{OW} / \mathrm{OB}$, with no significant difference between girls and boys (Mann-Whitney $\mathrm{U}$ test, $\mathrm{p}=0.885$ ). The full distribution of children between weight categories is shown in table 2.

There were no significant differences between the sexes in the number of days the activity belt was worn or the total volume of activity (mean cpm; table 3 ).

Table 1 Participant characteristics (median and IQR), by sex

\begin{tabular}{|c|c|c|c|c|c|c|c|}
\hline \multirow[b]{2}{*}{ Height $(\mathrm{cm})$} & \multicolumn{2}{|c|}{$\begin{array}{l}\text { Combined* }^{*} \\
(n=425)\end{array}$} & \multicolumn{2}{|c|}{$\begin{array}{l}\text { Boys }(n=211) \\
(49.6 \%)\end{array}$} & \multicolumn{2}{|c|}{$\begin{array}{l}\text { Girls }(n=214) \\
(50.4 \%)\end{array}$} & \multirow{2}{*}{$\frac{\text { p Value }}{0.039}$} \\
\hline & 1.24 & $\begin{array}{l}1.21 \\
1.29\end{array}$ & 1.26 & $\begin{array}{l}1.22 \\
1.29\end{array}$ & 1.24 & $\begin{array}{l}1.21 \\
1.28\end{array}$ & \\
\hline Weight (kg) & 26.4 & $\begin{array}{l}22.7 \\
28.7\end{array}$ & 25.7 & $\begin{array}{l}23.0 \\
29.1\end{array}$ & 25.0 & $\begin{array}{l}22.5 \\
28.4\end{array}$ & 0.264 \\
\hline Waist (cm) & 55.7 & $\begin{array}{l}52.6 \\
59.0\end{array}$ & 56.5 & $\begin{array}{l}53.5 \\
59.4\end{array}$ & 54.8 & $\begin{array}{l}52.1 \\
58.7\end{array}$ & 0.006 \\
\hline BMI $\left(\mathrm{kg} / \mathrm{m}^{2}\right)$ & 16.2 & $\begin{array}{l}15.3 \\
17.8\end{array}$ & 16.1 & $\begin{array}{l}15.4 \\
17.8\end{array}$ & 16.3 & $\begin{array}{l}15.2 \\
17.8\end{array}$ & 0.878 \\
\hline
\end{tabular}

${ }^{*} n$ For individual measures varying from 421 to 425 . Mann-Whitney $U$ tests performed. 
Table 2 Distribution of children between weight categories, by sex

\begin{tabular}{|c|c|c|c|c|c|c|}
\hline & \multicolumn{2}{|c|}{ Combined } & \multicolumn{2}{|c|}{ Boys (49.6\%) } & \multicolumn{2}{|c|}{ Girls (50.4\%) } \\
\hline & $\mathbf{n}$ & Per cent & $\bar{n}$ & Per cent & $\bar{n}$ & Per cent \\
\hline Underweight & 3 & 0.7 & 1 & 0.5 & 2 & 0.9 \\
\hline Healthy weight & 320 & 75.3 & 160 & 75.8 & 160 & 74.8 \\
\hline Overweight & 75 & 17.6 & 35 & 16.6 & 40 & 18.7 \\
\hline Obese & 27 & 6.4 & 15 & 7.1 & 12 & 5.6 \\
\hline Total & 425 & 100.0 & 211 & 100.0 & 214 & 100.0 \\
\hline
\end{tabular}

Levels of activity in general were low, as reported previously; ${ }^{12}$ only 31 children $(7 \%)$ achieved an average of at least 60 min MVPA/ day, 23 boys and 8 girls. Only two children $(0.5 \%)$ accumulated at least $60 \mathrm{~min}$ on each day they wore the accelerometer. The majority of time was spent in SB (median $78 \%$ of wear time, equivalent to around $8.6 \mathrm{~h} /$ day). When looking at the differences between weekend and weekday activity, volume of activity (cpm) was similar, and slightly but significantly more MVPA was taken on weekdays $(\mathrm{p}<0.0001$; data not shown). Girls had a greater volume of activity on weekends but a lower time spent in MVPA, suggesting that the majority of their activities are in the sedentary or light intensity categories. Boys spent significantly more time in MVPA on weekdays than girls.

Dietary intake was similar for boys and girls (table 3). Children consumed a median of 1.7 portions of fruit and vegetables daily (or 2.1 portions when including fruit juice), with just $13 / 425$ children $(3.1 \%)$ consuming '5 a day'. On average, children ate $5.0 \mathrm{HI}$ foods and 5.3 UI foods daily.

Table 4 displays the distribution of $\mathrm{OW} / \mathrm{OB}$ by diet and activity group.

$13 \%$ of healthy weight boys were in the 'active' PA category, compared with just $4 \%$ of OW/OB boys. $48 \%$ of healthy weight boys were inactive compared with $76 \%$ of OW/OB boys. There was less variation for girls, as only eight girls in total were in the active category. In total, $59 \%$ of healthy weight girls were in the inactive category compared with $71 \%$ of OW/OB girls.

Compared with the reference group (inactive), children in the moderately active group had a significantly lower risk of being $\mathrm{OW} / \mathrm{OB} \quad(\mathrm{OR}=0.44,0.26$ to 0.74 (table 5)).

Table 3 Comparison of physical activity, sedentary behaviour (SB) and dietary intake between sexes (median and IQR unless otherwise specified)

\begin{tabular}{|c|c|c|c|c|c|c|c|}
\hline & $\begin{array}{l}\text { Combined } \\
(n=425)\end{array}$ & & $\begin{array}{l}\text { Boys } \\
(n=211)\end{array}$ & & $\begin{array}{l}\text { Girls } \\
(n=214)\end{array}$ & & p Value \\
\hline \multicolumn{8}{|l|}{ Physical activity/SB } \\
\hline $\begin{array}{l}\text { Number of days } \\
\text { accelerometer worn }\end{array}$ & 7 & 6,7 & 7 & 6,7 & 7 & 6,7 & 0.380 \\
\hline Hours worn/day & 11.3 & $10.6,11.9$ & 11.4 & $10.7,12.0$ & 11.1 & $10.4,11.8$ & 0.077 \\
\hline Mean cpm/day & 727 & 604,878 & 740 & 624,881 & 718 & 591,868 & 0.313 \\
\hline MVPA (min/day) & 26 & 18,38 & 28 & 19,43 & 25 & 16,36 & 0.020 \\
\hline $\begin{array}{l}\text { Percentage of time in } \\
\text { MVPA }\end{array}$ & 3.9 & $2.6,5.7$ & 4.2 & $2.7,6.3$ & 3.8 & $2.5,5.5$ & 0.043 \\
\hline Percentage of time SB & 77.7 & $73.6,81.8$ & 76.9 & $71.9,80.8$ & 78.4 & $74.6,82.7$ & 0.002 \\
\hline $\begin{array}{l}\text { Achieved } 60 \mathrm{~min} / \text { day MVPA } \\
(\mathrm{n}, \%)^{*}\end{array}$ & 31 & 7.3 & 23 & 10.9 & 8 & 3.7 & 0.005 \\
\hline \multicolumn{8}{|l|}{ Dietary intake } \\
\hline $\begin{array}{l}\text { Portions of fruit and } \\
\text { vegetables consumed/day }\end{array}$ & 1.7 & $1.1,2.5$ & 1.7 & $1.0,2.5$ & 1.8 & $1.2,2.5$ & 0.211 \\
\hline $\begin{array}{l}\text { Portions of fruit and } \\
\text { vegetables consumed/day } \dagger\end{array}$ & 2.1 & $1.4,3.0$ & 2.0 & $1.3,2.9$ & 2.2 & $1.4,3.1$ & 0.224 \\
\hline $\begin{array}{l}\text { Ate } 5 \text { portions of fruit and } \\
\text { vegetables/day }(n, \%) \dagger\end{array}$ & 13 & 3.1 & 8 & 3.8 & 5 & 2.3 & 0.384 \\
\hline $\begin{array}{l}\text { Number of healthy indicator } \\
\text { foods/day }\end{array}$ & 5.0 & $3.8,6.5$ & 5.0 & $3.8,6.5$ & 5.1 & $3.8,6.5$ & 0.342 \\
\hline $\begin{array}{l}\text { Number of unhealthy } \\
\text { indicator foods/day }\end{array}$ & 5.3 & $4.3,6.3$ & 5.5 & $4.3,6.3$ & 5.3 & $4.3,6.3$ & 0.496 \\
\hline
\end{tabular}


Table 4 Distribution of OW/OB by PA and dietary category (n, \%)

\begin{tabular}{|c|c|c|c|c|c|c|c|c|}
\hline \multirow[b]{3}{*}{ PA category } & \multicolumn{4}{|c|}{ Healthy weight $(323,76.0)$} & \multicolumn{4}{|c|}{ Overweight or obese $(102,24.0)$} \\
\hline & \multicolumn{3}{|c|}{ Dietary pattern } & \multirow[b]{2}{*}{ Total } & \multicolumn{3}{|c|}{ Dietary pattern } & \multirow[b]{2}{*}{ Total } \\
\hline & Unhealthy & Mixed & Healthy & & Unhealthy & Mixed & Healthy & \\
\hline \multicolumn{9}{|l|}{ Boys $(211,49.6)$} \\
\hline Inactive & $27,16.8$ & $33,20.5$ & $18,11.2$ & $78,48.4$ & $11,22.0$ & $13,26.0$ & $14,28.0$ & $38,76.0$ \\
\hline Moderately active & $17,10.6$ & $28,17.4$ & $17,10.6$ & $62,38.5$ & $2,4.0$ & $7,14.0$ & $1,2.0$ & $10,20.0$ \\
\hline Active & $9,5.6$ & $10,6.2$ & $2,1.2$ & $21,13.0$ & $0,0.0$ & $1,2.0$ & $1,2.0$ & $2,4.0$ \\
\hline Total & $53,32.9$ & $71,44.1$ & $37,23.0$ & $161,100.0$ & $13,26.0$ & $21,42.0$ & $16,32.0$ & $50,100.0$ \\
\hline \multicolumn{9}{|l|}{ Girls $(214,50.4)$} \\
\hline Inactive & $27,16.7$ & $29,17.9$ & $40,24.7$ & $96,59.3$ & $9,17.3$ & $18,34.6$ & $10,19.2$ & $37,71.2$ \\
\hline Moderately active & $17,10.5$ & $31,19.1$ & $12,7.4$ & $60,37.0$ & $4,7.7$ & $4,7.7$ & $5,9.6$ & $13,25.0$ \\
\hline Active & $1,0.6$ & $3,1.9$ & $2,1.2$ & $6,3.7$ & $0,0.0$ & $2,3.8$ & $0,0.0$ & $2,3.8$ \\
\hline Total & $45,27.8$ & $63,38.9$ & $54,33.3$ & $162,100.0$ & $13,25.0$ & $24,46.2$ & $15,28.8$ & $52,100.0$ \\
\hline
\end{tabular}

Results for children in the active group $(\geq 60 \mathrm{~min}$ MVPA/ day, OR=0.34, 95\% CI 0.12 to 1.02 ) approached significance $(p=0.054)$. Similar results were seen after adjusting for sex. When analysing girls and boys separately, the association between $\mathrm{PA}$ and risk of $\mathrm{OW} / \mathrm{OB}$ remained only for boys. Boys who were moderately active had an OR of 0.33 (0.15 to 0.72 ) for risk of $\mathrm{OW} / \mathrm{OB}$ $(\mathrm{p}=0.005)$, and boys in the active category had an OR of 0.20 (0.04 to $0.88 ; \mathrm{p}=0.033)$, compared with the inactive group. Moderately active girls had an OR of $0.56(0.28$ to $1.14 ; \mathrm{p}=0.112)$ and active girls an $\mathrm{OR}$ of $0.86(0.17$ to 4.48; $\mathrm{p}=0.863$ ) for $\mathrm{OW} / \mathrm{OB}$ compared with inactive girls. Similar results were seen for activity when adjusting for diet group.

There was no influence of dietary pattern on risk of OW/OB: OR 1.27 (0.73 to $2.19 ; \mathrm{p}=0.40)$ for the mixed diet group, 1.28 ( 0.71 to 2.33$)$ for the healthy group $(\mathrm{p}=0.41)$ compared with the reference group (unhealthy diet; table 5), with similar results after adjusting for sex.

There was no evidence of an interaction between PA and food intake on risk of OW/OB $(\mathrm{p}=0.444)$.

\section{DISCUSSION}

Our results provide evidence that children in northeast England are not meeting the guidelines for PA and nutrition that are recommended for good health. Lack of MVPA was associated with an increased risk of being $\mathrm{OW}$ and $\mathrm{OB}$ in boys. The lack of association in girls could be due to the low numbers being sufficiently active.

The present study has limitations in terms of the ethnically homogeneous sample, which may limit the generalisability of the findings to other samples and settings. There was also a lack of variability in PA, with data skewed towards inactivity, particularly in girls. There are several cutpoints in use for classifying $\mathrm{MVPA}^{24}$ and the value of $3200 \mathrm{cpm}$ used in the current study was obtained through comparison with energy expenditure, ${ }^{16}$ and similar to those from other studies. ${ }^{15}$ Given the ongoing discussion regarding the choice of cutpoint, there may be no suitable cutpoint for all ages of childhood. As the data are cross-sectional, it is not possible to determine the direction of causality, which will be addressed by future follow-up. However, the strengths of this study include the relatively large sample size, the focused age of the children, and the use of objective measures of PA (accelerometry) combined with dietary observations is unique.

Few other studies have used objective methods to describe levels of habitual PA and SB in 6-8-year-olds in combination with dietary intake measures. Recent UK studies in 3-5-year-olds ${ }^{14}$ and $11-12$-year-olds ${ }^{25}$ which have used the same objective methods of PA measurement have found similarly low levels of PA with adherence to the $60 \mathrm{~min} /$ day recommendation of MVPA being achieved in $<5 \%$ of their samples. In contrast, UK studies which have used subjective methods (questionnaires) have generally

Table 5 Likelihood of being overweight or obese for different activity levels and dietary patterns (ORs and $95 \% \mathrm{Cl})$

\begin{tabular}{|c|c|c|c|c|c|c|}
\hline & Combined $(n=425)$ & p Value & Boys $(n=211)$ & p Value & Girls $(n=214)$ & p Value \\
\hline Inactive (reference) & 1 & & 1 & & 1 & \\
\hline Moderately active & $0.44(0.26$ to 0.74$)$ & 0.002 & 0.33 (0.15 to 0.72$)$ & 0.005 & $0.56(0.28$ to 1.14$)$ & 0.112 \\
\hline Active & $0.34(0.12$ to 1.02$)$ & 0.054 & $0.20(0.04$ to 0.88$)$ & 0.033 & 0.86 (0.17 to 4.48$)$ & 0.863 \\
\hline Unhealthy diet (reference) & 1 & & 1 & & 1 & \\
\hline Mixed diet & $1.27(0.73$ to 2.19$)$ & 0.40 & 1.21 (0.55 to 2.62$)$ & 0.637 & 1.32 (0.61 to 2.86$)$ & 0.485 \\
\hline Healthy diet & 1.28 (0.71 to 2.33$)$ & 0.41 & $1.76(0.76$ to 4.10$)$ & 0.188 & 0.96 (0.42 to 2.23$)$ & 0.927 \\
\hline
\end{tabular}


reported much higher levels of MVPA, for example, the Health Survey for England, which leads to overestimates of PA. ${ }^{12}$ Low levels of PA were present in our sample well before puberty, the period traditionally regarded as being associated with low levels of PA. In keeping with other studies, ${ }^{926}$ we found that boys were more active than girls, and the lack of association of PA on risk of OW/OB in girls as compared with boys suggests further work is required into the mechanisms by which increasing $\mathrm{PA}$ and/or decreasing $\mathrm{SB}$ reduces risk of $\mathrm{OW} / \mathrm{OB}$ in children. Few studies have looked at the relationship between the '60 min' guidelines and body composition. Martinez-Gomez et $a l^{27}$ reported that $60 \mathrm{~min} /$ day MVPA could discriminate between normal weight and OW/OB adolescents (mean age 14.7 years), however they used a lower cutpoint for MVPA of $2000 \mathrm{cpm}$, compared with the $3200 \mathrm{cpm}$ used in the present study. This resulted in average MVPA/ day of $66 \mathrm{~min}$ for boys and $50 \mathrm{~min}$ for girls. ${ }^{27}$ Recent evidence using $3200 \mathrm{cpm}$ as the MVPA cutpoint for 10-year-olds in France ${ }^{28}$ found that only $10 \%$ of the 'normal weight' children reached $60 \mathrm{~min} /$ day, but $44 \%$ did at least $30 \mathrm{~min} /$ day. In addition, although only $5 \%$ of OW/OB children did at least $60 \mathrm{~min} /$ day MVPA, $34 \%$ reached $30 \mathrm{~min} /$ day. $^{28}$ Our results show that this lower recommendation could still have benefits in terms of body composition, particularly for boys.

While it is generally accepted that PA decreases with age ${ }^{29}$ pinpointing the age when the decrease starts is important for targeted interventions. Our results suggest that even at the age of 7 years, PA levels are far lower than recommended. The great proportion of time spent sedentary by both sexes is concerning-in both sexes almost $7 \mathrm{~h} /$ day were spent with no translocation of the trunk. ${ }^{15}$ Both sexes took part in more MVPA on weekdays than weekends, highlighting the role the school environment plays in maintaining activity levels, and that more needs to be done to increase activity on weekends. The crosssectional nature of the present study means we cannot say whether the children have already started to reduce their activity. However, data we have published from the cohort at a 2-year follow-up show a decrease in MVPA from age 7 to 9 years, and the decrease in MVPA associated with an increase in BMI-z score in boys. ${ }^{30} 31$

The low consumption of fruit and vegetables, and the relatively high consumption of an unhealthy diet in this sample is cause for concern, despite the lack of association between the 'healthy' or 'unhealthy' categories and risk of $\mathrm{OW} / \mathrm{OB}$. The lack of association between dietary variables and risk of OW/OB in this study, as in others, may be due to the lack of individual portion sizes which prohibited the assessment of energy intake. The dietary assessment tool used in this study allowed direct observation of intake but applied standard portion sizes from a previous National Diet and Nutrition Survey which used a weighed intake method. ${ }^{21}$ The amount for a 'portion' of fruit and vegetables was set at $80 \mathrm{~g}$, which is considered suitable for children aged over 11 years. ${ }^{32}$ A lower amount may be more suitable for children under 11 years, but as this has not yet been identified, ${ }^{32} 80 \mathrm{~g}$ was used in this analysis. It is possible that OW children are eating larger portions of healthy foods, or the parents are aware of their child's OW and have reduced food intake accordingly. There may also be an element of misreporting or optimistic bias if the parent believes their child is OW and eats either to excess or 'unhealthily'. Foods in the current study were assigned to the 'healthy' or 'unhealthy' group based on a combination of current national guidelines for consumption and restriction ${ }^{7}$ according to nutritional content. Since these analyses were performed, Frémeaux et a $\mathrm{l}^{33}$ have published a longitudinal factor analysis of English children's food intake from age 5 to 13 years. They reported the emergence of two main diet types that matched almost identically with ours. ${ }^{33}$ Recent evidence from Scottish 5-11year-olds did not find an association between dietary patterns and $\mathrm{BMI}$ or $\mathrm{PA},{ }^{11}$ and observed an inverse association between 'screen time' and healthier eating patterns (diet measured with food frequency questionnaire (FFQ) and PA measured by Physical activity questionnaire, PAQ). The Avon Longitudinal Study of Parents and Children (ALSPAC) cohort in the UK was assessed for associations between PA and diet at age 10-11 years, and found only weak relationships between the two ${ }^{34}(3 \times 1$-day food diary at 10 years, accelerometry at 11 years). A Greek case-control study found a protective effect of $\mathrm{PA}^{35}$ on risk of $\mathrm{OW} / \mathrm{OB}$, and an increased risk with increased time spent watching $\mathrm{TV}$, and consumption of sugar-sweetened beverages (FFQ PAQ), an observation also reported in Spanish children (FFQ/PAQ) ${ }^{36}$ Others ${ }^{37}$ found an effect of SB on risk of $\mathrm{OW} / \mathrm{OB}$, but again no effect of diet composition (questionnaire). A varied food pattern plus a physically active lifestyle was inversely related to $\mathrm{OW}$ in French children (7-day food diary/PAQ) ${ }^{38}$ Similarly, reduced PA, but not excessive energy intake, was associated with increased risk of $\mathrm{OB}$ in Turkish children (3-day food diary/PAQ) ${ }^{39}$ However, these studies included a wide age range of children, and PA and $\mathrm{SB}$ were measured objectively only in the ALSPAC cohort, ${ }^{34}$ so our observations strengthen the evidence base for the protective effects of $\mathrm{PA}$ on risk of $\mathrm{OW} / \mathrm{OB}$.

In conclusion, children in northeast England have extremely low levels of habitual MVPA, high levels of SB and consume a diet low in fruit and vegetables but high in foods associated with an unhealthy diet. Increased PA was associated with reduced risk of $\mathrm{OW} / \mathrm{OB}$ in boys. Further work is required to uncover the associations of $\mathrm{PA} /$ diet and $\mathrm{OW} /$ $\mathrm{OB}$ in girls and the longitudinal associations between PA/ diet and $\mathrm{OW} / \mathrm{OB}$ in boys and girls. These observations give cause for concern in relation to their current and future risk of cardiovascular diseases, diabetes and OB. Our observations suggest that UK government targets in relation to levels of PA and nutrition among children are not being met.

Acknowledgements The authors acknowledge the support of an External Reference Group in conducting the study. They appreciate the support of Gateshead Health NHS Foundation Trust, Gateshead Education Authority and local schools. They also thank the research team for their effort. Thanks are especially due to the Gateshead Millennium Study families and children for their participation in the study. 
Collaborators The Gateshead Millennium Study Core Team: AJA, Anne Dale, Robert Drewett, Ann Le Couteur, Paul McArdle, KNP, MSP, JJR and Charlotte Wright.

Contributors AJA and KNP were responsible for the study conception and design, manuscript drafting and revision. AJA is the study guarantor. JJR and MSP were responsible for the study conception and design, analysis and interpretation of the data, manuscript drafting and revision. LB, ARJ and JR were responsible for data acquisition, analysis and interpretation of the data; manuscript drafting and revision. All authors have had full access to all of the data in the study and take responsibility for the integrity of the data and the accuracy of the data analysis.

Funding This work was supported by the National Prevention Research Initiative (NPRI) grant number G0 501306. The Gateshead Millennium Study is supported by a grant from the NPRI (incorporating funding from British Heart Foundation; Cancer Research UK; Department of Health; Diabetes UK; Economic and Social Research Council; Food Standards Agency; Medical Research Council; Research and Development Office for the Northern Ireland Health and Social Services; Chief Scientist Office, Scottish Government Health Directorates; Welsh Assembly Government and World Cancer Research Fund). The cohort was first established with funding from the Henry Smith Charity and Sport Aiding Research in Kids (SPARKS) and followed up with grants from Gateshead NHS Trust R\&D, Northern and Yorkshire NHS R\&D, and Northumberland, Tyne and Wear NHS Trust.

Competing interests None.

Ethics approval Gateshead and South Tyneside Local National Health Service Research Ethics Committee.

Provenance and peer review Not commissioned; externally peer reviewed.

Data sharing statement No additional data are available.

Open Access This is an Open Access article distributed in accordance with the terms of the Creative Commons Attribution (CC BY 3.0) license, which permits others to distribute, remix, adapt and build upon this work, for commercial use, provided the original work is properly cited. See: http:// creativecommons.org/licenses/by/3.0/

\section{REFERENCES}

1. Department of Health. Healthy lives, healthy people: a call to action on obesity in England. London: Department of Health, 2011.

2. http://www.letsmove.gov. Let's Move!, 2010, p Website for Michelle Obama's campaign to reduce childhood obesity.

3. The Health and Social Care Information Centre. National Child Measurement Programme: England, 2011/2012 school year. 2012.

4. Chief Medical Officers of England Scotland Wales and Northern Ireland. Start active, stay active: a report on physical activity from the four home countries' chief medical officers. London: Department of Health, 2011.

5. Strong WB, Malina RM, Blimkie CJR, et al. Evidence based physical activity for school-age youth. J Pediatr 2005;146:732-7.

6. Health Survey for England 2008. Volume 1: physical activity and fitness. A survey carried out on behalf of the NHS Information Centre. Craig R, Mindell J, Hirani V, eds. NHS Information Centre, 2009

7. NHS Choices. Healthy Eating. 2013. http://www.nhs.uk/LiveWell/ healthy-eating/Pages/Healthyeating.aspx (accessed 16 Jan 2013).

8. Department of Health. National Diet and Nutrition Survey. Headlin results from Years 1, 2 and 3 (combined) of the Rolling Programme (2008/2009 -2009/10). Bates B, Lennox A, Bates C, Swan G, eds. London: HMSO, 2011. https://www.gov.uk/government/uploads/ system/uploads/attachment_data/file/216484/dh_128550.pdf (accessed 25 May 2014).

9. Janz KF, Kwon S, Letuchy EM, et al. Sustained effect of early physical activity on body fat mass in older children. Am J Prev Med 2009;37:35-40.

10. Must A, Barish EE, Bandini LG. Modifiable risk factors in relation to changes in BMI and fatness: what have we learned from prospective studies of school-aged children [quest]. Int J Obes 2009;33:705-15.

11. Craig LCA, McNeill G, Macdiarmid JI, et al. Dietary patterns of school-age children in Scotland: association with socio-economic indicators, physical activity and obesity. Br J Nutr 2009;103:319-34.
12. Basterfield L, Adamson AJ, Parkinson KN, et al. Surveillance of physical activity in the UK is flawed: validation of the Health Survey for England Physical Activity Questionnaire. Arch Dis Child 2008;93:1054-8.

13. Parkinson KN, Pearce MS, Dale A, et al. Cohort profile: the Gateshead Millennium Study. Int J Epidemiol 2010;40:308-17.

14. Reilly JJ, Jackson DM, Montgomery C, et al. Total energy expenditure and physical activity in young Scottish children: mixed longitudinal study. Lancet 2004;363:211-12.

15. Reilly JJ, Penpraze V, Hislop J, et al. Objective measurement of physical activity and sedentary behaviour: review with new data. Arch Dis Child 2008:93:614-19.

16. Puyau MR, Adolph AL, Vohra FA, et al. Validation and calibration of physical activity monitors in children. Obes Res 2002;10:150-7.

17. Reilly JJ, Coyle J, Kelly L, et al. An objective method for measurement of sedentary behavior in 3- to 4-year olds. Obes Res 2003;11:1155-8.

18. Corder K, Brage S, Ramachandran A, et al. Comparison of two Actigraph models for assessing free-living physical activity in Indian adolescents. J Sports Sci 2007;25:1607-11.

19. Basterfield L, Adamson AJ, Pearce MS, et al. Stability of habitua physical activity and sedentary behavior monitoring by accelerometry in 6-8 year olds. J Phys Act Health 2011;8:543-7.

20. Adamson AJ, Griffiths JM, Carlin LE, et al. FAST: food assessment in schools tool. Proc Nutr Soc 2003;62:84A.

21. Gregory JR, Lowe S, Bates CJ, et al. National Diet and Nutrition Survey: young people aged 4 to 18 years. Volume 1: report of the Diet and Nutrition Survey. London: The Stationary Office, 2000.

22. Cole TJ, Bellizzi MC, Flegal KM, et al. Establishing a standard definition for child overweight and obesity worldwide: international survey. BMJ 2000;320:1240-3.

23. Cole TJ, Flegal KM, Nicholls D, et al. Body mass index cut offs to define thinness in children and adolescents: international survey. BMJ 2007;335:194-7.

24. Trost SG, Loprinzi PD, Moore R, et al. Comparison of accelerometer cut points for predicting activity intensity in youth. Med Sci Sports Exerc 2011;43:1360-8.

25. Riddoch CJ, Mattocks C, Deere K, et al. Objective measurement of levels and patterns of physical activity. Arch Dis Child 2007;92:963-9.

26. Riddoch CJ, Andersen LB, Wedderkopp N, et al. Physical activity levels and patterns of 9-and 15-yr-old European children. Med Sci Sports Exerc 2004;36:86-92.

27. Martinez-Gomez D, Ruiz JR, Ortega FB, et al. Recommended levels of physical activity to avoid an excess of body fat in European adolescents: the HELENA Study. Am J Prev Med 2010;39:203-11.

28. Apete GK, Zitouni D, Hubert $\mathrm{H}$, et al. Compliance of children in northern France with physical activity recommendations. Perspect Public Health 2012;132:81-8.

29. Jago R, Wedderkopp N, Kristensen PL, et al. Six-year change in youth physical activity and effect on fasting insulin and HOMA-IR Am J Prev Med 2008;35:554-60.

30. Basterfield L, Adamson AJ, Frary JK, et al. Longitudinal study of physical activity and sedentary behavior in children. Pediatrics 2011;127:E24-30.

31. Basterfield L, Pearce MS, Adamson AJ, et al. Physical activity, sedentary behavior, and adiposity in English children. Am J Prev Med 2012:42:445-51.

32. Ruxton CHS, Derbyshire E. Diet adequacy in UK schoolchildren Nutr Food Sci 2011;41:20-33.

33. Frémeaux AE, Hosking J, Metcalf BS, et al. Consistency of children's dietary choices: annual repeat measures from 5 to 13 years (EarlyBird 49). Br J Nutr 2011;106:725-31.

34. Jago R, Ness AR, Emmett $P$, et al. Obesogenic diet and physical activity: independent or associated behaviours in adolescents? Public Health Nutr 2010;13:673-81.

35. Papandreou D, Malindretos P, Rousso I. Risk factors for childhood obesity in a Greek paediatric population. Public Health Nutr 2010; first view: $1-5$

36. Ochoa MC, Moreno-Aliaga MJ, Martínez-González MA, et al. Predictor factors for childhood obesity in a Spanish case-control study. Nutrition 2007;23:379-84.

37. Lagiou A, Parava M. Correlates of childhood obesity in Athens, Greece. Public Health Nutr 2008;11:940-5.

38. Lioret S, Touvier M, Lafay L, et al. Dietary and physical activity patterns in French children are related to overweight and socioeconomic status. J Nutr 2008;138:101-7.

39. Garipagaoglu M, Budak N, Süt N, et al. Obesity risk factors in Turkish children. J Pediatr Nurs 2009;24:332-7. 